\title{
Mapping and assessing sexual and reproductive health policy changes over time in Colombia: measuring their impact on pregnancy terminations
}

José Ignacio Nazif-Munoz (i) ${ }^{1 凶} \&$ Rose Chabot $^{2}$

Sexual and reproductive health and rights policies (SRHRPs) and their association with reproductive and non-reproductive behavior require precise theoretical and methodological frames. By studying the case of Colombia, we move forward with a comprehensive framework that considers simultaneously multiple SRHRP conceptualizations and their impacts over time on induced pregnancy terminations (IPT). With a mixed-method approach, we first map the evolution of SRHRPs and then analyze their direct and indirect effects on IPTs, using the provision of contraceptive methods by the government, female use of contraceptive methods, and conversations with health professionals in a mediation approach. We build a unique data set from more than 2100 policy documents, and then use data on 81,760 women (20-40 years) from four waves (2000-2015) of Colombia's Demographic and Health Surveys. We find that SRHRPs are directly associated with an $18 \%$ reduction in reported IPTs. Associations between these variables are explained by the increased use of modern contraceptive methods (6\%), and the government's provision of those contraceptive methods (13\%). Studies interested in the impact of SRHRPs need to consider not only the direct effects of legal changes on abortion outcomes but also show changes over time may operate through different sub-programs embedded in these policies, such as access to contraceptive methods and family planning. This will add further nuances to how SRHRPs are both multilayered and implemented.

\footnotetext{
${ }^{1}$ Faculté de Médecine et des Sciences de la Santé, Université de Sherbrooke, Sherbrooke, Canada. ${ }^{2}$ Department of Political Science, McGill University,

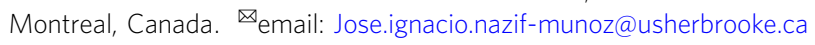




\section{Introduction}

ccess to contraceptive methods, family planning, comprehensive sexual education, as well as the prevention, punishment, and eradication of violence against women constitute some of the key instruments promoted through the Sustainable Development Goals since 2015, particularly those defined in its SDG 5: achieve gender equality and empower all women and girls (UNFPA, 2021). As the global agenda on sexual and reproductive health and rights evolves, awareness surrounding their distinct, yet complementary role in promoting women's wellbeing and empowerment across their life course has grown amongst Latin American states (Starrs et al., 2018). More specifically, states' approaches to sexual and reproductive health and rights policies (SRHRP) have become increasingly comprehensive since the beginning of the 2000s in this region (FormanRabinovici and Sommer, 2018).

Those complex policy infrastructures immediately implicate tensions on how women delineate, intersect with, confront, negotiate and/or accept states' actions-which are instituted to purposely (vertically or horizontally) regulate reproductive knowledge and/or behaviors (Lane, 1994). Further, how collectively women react will have an impact on how SRHRPs are historically redefined and reshaped (Budde and Heichel, 2017; Staggenborg and Skoczylas, 2017). SRHRP may start in one direction, however social forces can delay their impact, transform their initial meaning, and change their content altogether (Reingold et al., 2021). For instance, from high natalist to Malthusian logics informing twentieth-century SRHRPs, one can observe slow shifting towards a "reproductive rights" paradigm (Jaffré and Suh, 2016). Indeed, contributions made by feminist and women's rights activists to the 1994 Cairo International Conference on Population and Development and the 1995 Beijing Platform for Action marked the beginning of a slow global shifting towards a reproductive rights paradigm, along with a more recent emphasis on sexual rights in the last decade (Jaffré and Suh, 2016; Stephenson et al., 2017). Yet within these transitions, trails of past SRHRPs may remain active.

There are also multiple layers that may shape the evolution of SRHRPs since these may be instituted in different state dispositives such as laws, court rulings, programs, and budgets. Depending on jurisdictions, some of these tools can be implemented at the national, provincial, and local levels, or in specific governmental bureaus such as ministries of health, or women ministerial bureaus, and despite efforts for transversal action, low-resourced and territorially unequal coordinating "women's" or "gender equality" institutions may create further contradictions on how states operate while mainstreaming gender equality policies (Denisov et al., 2012; OECD, 2020). The interaction of SRHRPs with women's individual and collective actions over time thus makes our understanding of these social phenomena rather challenging.

While SRHRPs in Latin America have become increasingly comprehensive and diverse, high contestation from conservative sectors has delayed the breadth and depth of this process (Forman-Rabinovici and Sommer, 2018). Indeed access to safe abortions remains extremely limited and unwanted pregnancy rates are amongst the highest worldwide (Casterline and Mendoza, 2009; Ganatra et al., 2017). As low quality and limited access to state services are widespread, it is unclear to what extent SHRPRs may have improved women's empowerment, understood as "a process transitioning from the existence of choice (autonomy) to exercise of choice (self-efficacy, decision-making, negotiation), and, ultimately, to the achievement of choice" in their sexual and reproductive health (Karp et al., 2020, p. 1).

In this article, we tackle the following research question: how have SRHRPs interacted with women's reproductive health over time? For this, we focus on Colombia, between 2000 and 2015. During this time, Colombia introduced unprecedented changes to develop a comprehensive set of SRHRPs. On May 10, 2006, Colombia's Constitutional Court partially decriminalized abortion in cases of danger for the person's health or life, severe fetal malformation incompatible with life, or sexual violence involving rape, incest, or forced insemination. Until that decision, Colombian law prohibited abortion in all circumstances (Maldonado, 2019). This event was followed by multiple state and collective actions, which ultimately ended with the new Sexual and Reproductive Health National Public Policy for the 2007-2010 and 2014-2021 periods. As such, this country provides us with a unique opportunity to explore how SRHRP's multiple conceptualizations can be associated with different social mechanisms of women's individual choices in this realm.

\section{A twofold analytical frame: between evolution of SRHRPs and social mechanisms}

Depending on theoretical frames and data availability, studies focusing on understanding how SRHRPs interrelate with different sexual and reproductive health outcomes, rarely attempt to bring the multiple layers that conform these policies. For instance, an important part of the literature interested in studying how changes in abortion policy may affect induced pregnancy terminations (IPT), generally assumes that these policies directly affect individual choices or that they are embedded within a social system in which it is expected to observe unidirectional changes (as if implementation within jurisdictions was a monotonic process whereby for instance access to safe services is taken for granted (Ganatra et al., 2017)). However, existing research shows that beyond the legal setting, women's decisions to interrupt a pregnancy, in or outside the healthcare system, is driven by multiple factors ranging from the micro to the macrolevel, including parity and lifestyle preferences across class and age ranges but also life circumstances such as unwanted pregnancy, contraceptive failure, economic vulnerability, or domestic violence (Bélanger and Flynn, 2009; Pallitto and O'Campo, 2004). Indeed, in the United States (US) (Blank et al., 1994), or in Eastern Europe (Levine and Staiger, 2004), some studies have suggested that policies restricting abortion are associated with reductions in abortions rates, whereas in Spain, one specific type of decriminalization abortion policy was not associated with abortion outcomes (Peirö et al., 2001). Conversely, in a study considering 136 countries (Sedgh et al., 2012), it was concluded that less restrictive abortion laws were associated with reductions in IPTs. Part of these theoretical challenges may explain the presence of inconsistent findings, as well as the methodological limitations associated with the use of indirect indicators such as abortion-related hospitalizations (Singh and Wulf, 1994) or health care professionals surveys (Prada et al., 2011, 2012) which tend to obscure abortions in the informal sector and often do not distinguish between spontaneous and IPT. Nevertheless, even under the case in which abortion liberalization may increase access to health care and safer abortion procedures (Chemlal and Russo, 2019), it remains unclear how these legal frameworks affect women's decision to interrupt a pregnancy, and through which mechanisms.

Thus, when considering the path between SRHRPs and individual abortion outcomes, we argue a twofold consideration should be guiding studies more consistently. Firstly, following van der Heijden and Kuhlmann (2017), we should frame questions on how SHRRPs evolve, drift, or even decelerate or layer among each other. To effectively capture policy interactions and patterns of change, we should have the capacity to operationalize the 
possibilities of policy displacement (absence and presence of a radical policy change), policy layering (a sequence of changes to support an initial radical change), or policy drift (a sequence of changes to support an initial radical change is at certain points contested). More specifically not only SRHRPs change their approach, contents, and instruments over time, but when they do, other subsets of policies can be also transformed (Forman-Rabinovici and Sommer, 2018). In this regard, it is important to identify changes that may be simultaneously occurring within state tools that either reinforce or undermine circumstances to properly support abortions in public healthcare systems which may affect women's decisions (Benson, 2005). In Nepal, for instance, the abortion law enacted in 2002 (Muluki Ain 11th Amendment Bill) increased the provision of services, guidelines, and sex education programs offered to both women and health professionals (Samandari et al., 2012). Similar models have been reported in Romania and South Africa (Benson et al., 2011), in which for instance health providers were purposely trained in contraceptive counseling. However, changes over time may also implicate contractions of SRHRPs. In Mexico, a federal country, right after 2007 the Federal District effectively legalized firsttrimester abortions, other Mexican states simultaneously introduced heavier sanctions for this practice (Clarke and Mühlrad, 2018; Gutiérrez Vázquez and Parrado, 2016). A similar pattern occurred in the state of Texas (United States), when the enactment of several norms limited family planning providers to receive government funding and placed more stringent requirements on the functioning of abortion clinics (Fischer et al., 2018).

Secondly, to properly observe individual shifts derived from SRHRP's layering, drift, or displacement, some concatenation of social mechanisms must be in place (Gambetta, 1998). A first mechanism relates to how states' institutional responses and SRHRP implementation open or close possibilities for women in the exercise of their reproductive rights; a given public system may increase or reduce opportunities to improve knowledge regarding abortion and/or contraceptive methods, as well as the actual provision of reproductive health services. A second mechanism, derived from an SRHRP scenario in which institutional openings have occurred, suggests that access to contraceptive methods reduces the probability of unwanted pregnancy and so is the demand for induced abortions (Starbird et al., 2016). Deriving from the latter, abortion liberalization should lead to a reduction in informal sector abortions, which tend to be more unsafe and lead to a decrease in abortion-related morbidity and post-abortion health complication rates (Schiavon et al., 2012). Conversely, if SRHRP negatively displaces abortion rights, the two mechanisms described above can change their direction. Thus, the probabilities of unwanted pregnancy would increase since first, interactions between women and health professionals in which the dissemination of contraceptive knowledge and provision from the government occur would have decreased. Second, as the number of unintended pregnancies augments, induced abortions taking place in unsafe environments would be more frequent, which would ultimately increment abortionrelated morbidity and negative health outcomes (Ganatra and Faundes, 2016).

Our analytical frame allows us to study how SRHRP may have affected abortions, through shifts in women's contraceptive behavior (mechanism 1), access to contraceptive methods through government provision (mechanism 2), and/or through increases in the number of conversations about family planning between health professionals and women (mechanism 3). We hypothesize that in Colombia, a lower incidence of abortions will be detected as the country introduces an SRHRP framework close to the notion of layering as suggested by van der Heijden and Kuhlmann (2017). In short, a consistent increase in access, use, and effectiveness of contraceptive methods, and exposure to family planning conversations with health professionals will reduce unwanted pregnancies and contraceptive failures and in turn, women's incentives to pursue an abortion in potentially unsafe conditions.

\section{Methods}

We apply a mixed-method approach by integrating a policy selection process and quantitative approaches in the design and interpretation stages (Fetters et al., 2013). More specifically we carry out an exploratory sequential design (Onwuegbuzie et al., 2010), in which first we map how Colombia has built its SRHRPs over time (2000-2015). We then integrate the results of this stage by informing how three different operationalization of SRHRPs could be quantitatively associated with various outcomes of interest, using four DHS waves. Last, we apply multiple statistical tools to detect the extent to which SRHRPs capture variation in IPT, through changes in women's access to and practices of birth control, and family planning discussions with health professionals.

Policy selection process. To identify SRHRP variation over time, we concentrate on legislation, executive actions, and judicial decisions. Our search strategy was threefold: First, we collected primary sources on Colombia's Ministry of Justice Unique System of Legal Information (Sistema Único de Infomación Normativa, SUIN) (Ministry of Justice of Colombia, 2021) and the Supreme Court online jurisprudential repository (Supreme Court of Colombia, 2021). We searched for all documents (laws, decrees, and jurisprudence) produced between 2000 and 2015 (inclusion criterion \#1), using the keywords "reproductive health," "sexual health," and "abortion" (inclusion criterion \#2). The initial search results produced a total of 2144 potential official communications, laws, and policies, as well as a total of 171 potential jurisprudential materials (Supreme Court website). We relied on the results' titles and summary descriptions to filter and select the legally-binding laws, decrees, and jurisprudence (inclusion criterion \#3) and corresponding to each dimension of sexual and reproductive health and rights under consideration, that is, access to and regulation of abortion, contraception or birth control, family planning, sexual education, and services of attention to survivors of sexual violence (inclusion criterion \#4). Second, we triangulated and complemented the findings through the nongovernmental organization (NGO) La Mesa Por la Vida y la Salud de las Mujeres (2021), which has worked to support women's rights in Colombia since 1998 and has systematically compiled a diverse range of women's reproductive rights legal and judicial documents. Last, we also relied on Colombia's Ministry of Health and Social Protection (MHSP) analytical compilation of social reproductive health norms (González Vélez 2013) and other secondary literature (see Fig. 1 for further details).

\section{Quantitative approach}

Study population. We used four waves of Colombia's DHS (2000; 2004-2005; 2009-2010; 2015-2016). The DHS is a cross-sectional nationally representative household survey that collects health information through a face-to-face interview. This survey has covered 116 countries, many over several rounds of surveys producing trend data. Analyses over time and across and within countries are thus feasible (Khan and Hancioglu, 2019). A twostage cluster sampling design is employed to sample the households before collecting information on women (aged 15-49 years), men (aged 15-49), and their children (0-5 years). 81,760 women (20-40 years) in Colombia were participants of this study. We focus on women aged 20-40 to avoid potential biases from women at their extreme reproductive years who have differential 


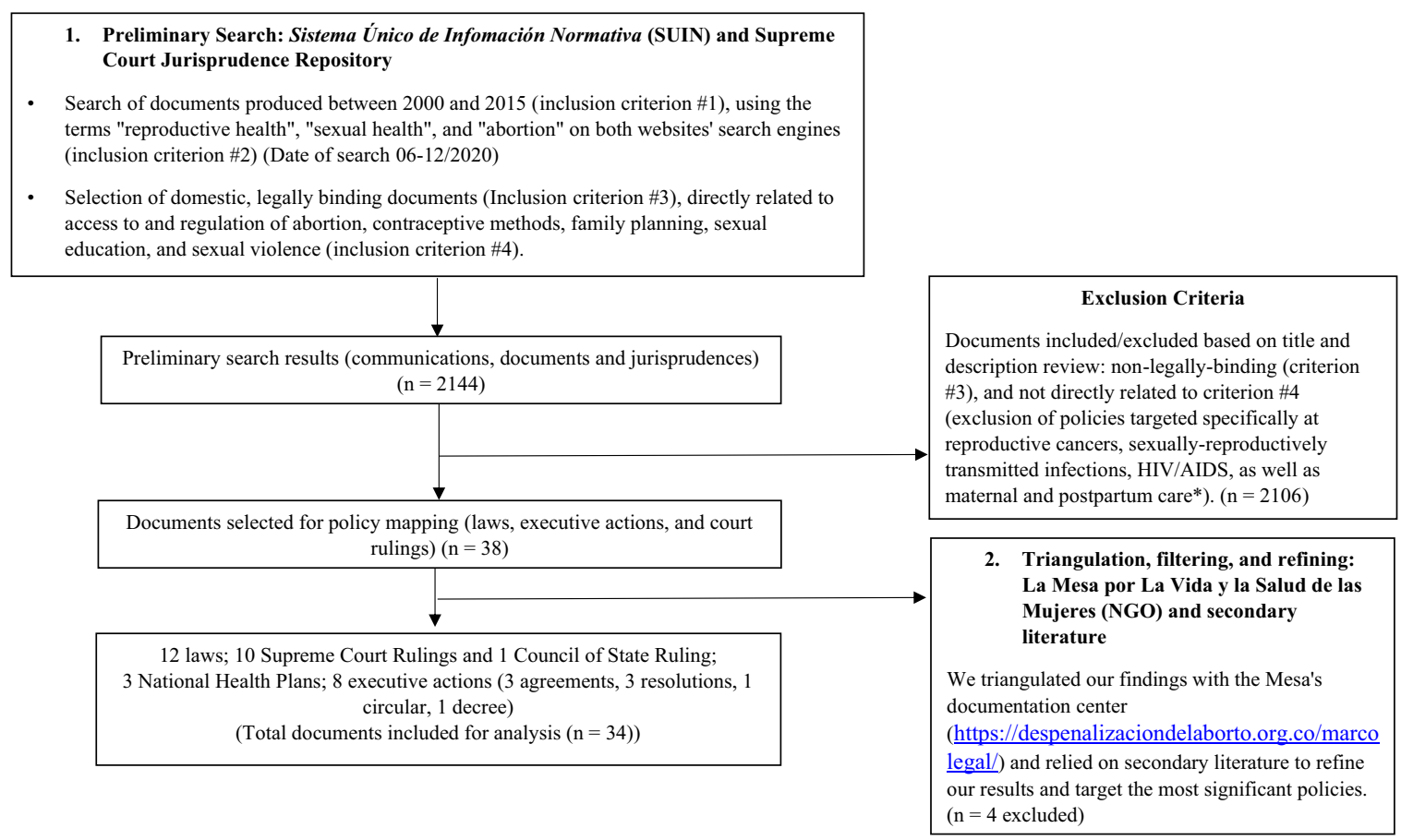

* Our exclusion criterion was chosen to maintain a manageable policy scope for this study; however, these important policies and issues are embedded in broader public policies, including the three selected National Public Health Plans (2002-2006; 2007-2010; 2014-2021).

Fig. 1 Two-step search strategy for the policy mapping.

fertility trends and contraceptive practices in Colombia (Flórez and Soto, 2007) and to account for homogeneous cohorts of women.

Measures. In Table 1 the operationalization for each variable used in the study is described.

Outcome variables. The DHS calendar variable tracks the month of each pregnancy termination reported by the respondent within 5 years prior to the interview. However, to distinguish spontaneous pregnancy terminations from IPTs, we build an estimated IPT variable based on Magnani, Magnani et al. (1996). We consider the following experiences: whether a woman declared the pregnancy termination has occurred during the first trimester of pregnancy to be associated with a contraceptive failure or to have occurred after the last pregnancy was declared to be undesired. This distinction allowed us to have three outcomes: (i) pregnancy termination after a contraceptive failure (APC); (ii) pregnancy termination due to an undesired pregnancy (PWU); and (iii) pregnancy termination due to APC or PWU. We also consider pregnancy terminations occurred in the second semester and results are available in supplementary material Table S1. Women's reports of IPTs may be measured with error; however, Brenes-Monge A et al. (2020) and Darney et al. (2020) suggest that cross-sectional surveys can be reliable instruments since differences over time are not consistently found when women report IPTs.

To measure women's birth control practices, we also use the DHS calendar variable to track the contraceptive method employed by each respondent monthly, for the duration of the calendar length. We use a fourfold classification: (i) modern methods, including female sterilization (tubal ligation), the contraceptive pill, intrauterine contraceptive device, injectables (Depo-Provera), implants (Norplant), female condom, male condom, diaphragm, contraceptive foam, and contraceptive jelly, lactational amenorrhea method, standard days method, and others such as cervical cap, contraceptive sponge; (ii) traditional methods, including periodic abstinence (rhythm, calendar method), withdrawal (coitus interruptus); (iii) folkloric methods, including spiritual methods of unproven effectiveness, such as herbs, amulets, or gris-gris; and (iv) not using any contraceptive method. We measure access to contraceptive methods by considering if these were provided by the government, or acquired in pharmacies, supermarkets, or private health facilities.

To understand if family planning outreach activities were carried out, we use a twofold classification: (i) experience of family planning outreach activities, including a home visit by a family planning worker in the 12 months preceding the interview and/or a visit by the respondent to a health facility for any reason in the twelve months preceding the interview in which she reports a family planning discussion with healthcare staff; and (ii) absence of family planning outreach activities, including the absence of any of these two activities.

Exposure variable. To construct our intervention policy, Colombia's SRHRP, we use the results from the policy mapping. More specifically, we map these interventions over time within the state of Colombia and echo three operationalizations as per suggested by van der Heijden and Kuhlmann (2017) when discussing possible policy unfolding: (i) policy displacement; (ii) policy layering; and (iii) policy layering with drift. Quantitatively, these three operationalizations follow different combinations of the numerical sequences using the years in which the surveys were carried out.

Mediator variables. Since we are interested in exploring pathways between policy and IPT, we also use women's contraceptive practices, access to contraceptive methods, and family planning outreach activities as mediators.

Control variables. Based on the extant literature (Blank et al., 1994; Chemlal and Russo, 2019; Clarke and Mühlrad, 2018; 


\section{Table 1 Description of the main variables.}

\section{Variables}

\section{Outcome variables}

After a contraceptive failure (APC)

If pregnancy was undesired (PWU)

APC or PWU

Contraceptive method

Access to contraceptive methods

Family planning outreach activities

Exposure variables

SRHRP as policy displacement (absence and presence of a radical policy change)

SRHRP as policy displacement with layering (sequence of policy changes to support an initial radical change)

SRHRP as policy displacement with layering and drift (sequence of policy changes to support an initial radical change is at certain points contested)

Control variables

Women's age

Women's education

Women's marital status

\section{Parity}

Intimate-partner/domestic violence

Urban

Region

\section{Operationalization}

$1=$ if pregnancy termination occurred in the first trimester and occurred after a contraceptive failure (respondent stops using a contraceptive method due to pregnancy), 0 otherwise

$1=$ if pregnancy termination occurred in the first trimester and was undesired, 0 otherwise

$1=$ if $\mathrm{APC}$ or PWU, 0 otherwise

$3=$ Modern method

$2=$ Traditional method

$1=$ Folkloric method

$0=$ No method employed (ref.)

$1=$ Provided by the government

$0=$ Acquired in a pharmacy; supermarket, or private health facility

$1=\mathrm{A}$ visit by a family planning worker in the twelve months preceding the interview, or a visit to a health facility for any reason in the twelve months preceding the interview and reporting that the health staff talked to the respondent about family planning, 0 otherwise (ref.)

$1=$ if year was after 2006, 0 otherwise (ref.)

$4=$ if year was 2016

$3=$ if year was 2015

$2=$ if year was 2010

$1=$ if year was 2009, 0 otherwise (ref.)

$3=$ if year was 2016

$2=$ if year was 2015

$1=$ if year was 2010 or 2009, 0 otherwise (ref.)

$4=40-44$ years

$3=35-39$ years

$2=30-34$ years

$1=25-29$ years

$0=19-24$ years (ref.)

Standardized highest education level attended:

$4=$ Higher

$3=$ Secondary

2 = Primary

$1=$ No education (ref.)

$4=$ Never in union $/$ married

$3=$ Widowed

2 = Separated / divorced/ not living together

$1=$ Living with partner

$\mathrm{O}=$ Married (ref.)

Total number of children ever born.

$1=$ respondent reports having (ever, in the past year, or before last year) been hurt by her partner/husband. Physical and psychological harms include respondent being pushed, shook, had something thrown at, slapped, punched with fits or hit, kicked, dragged, strangled, burnt, threatened with knife/gun/other weapon, had her arm twisted or hair pulled. undetermined time, 0 otherwise (ref.)

$1=$ if women lived in urban area

$0=$ if women lived in urban area (ref.)

$6=$ Orinoquia/Amazonia

$5=$ Pacífica

$4=$ Oriental

$3=$ Central

2 = Bogotá (ref.)

$1=$ Atlántica

SRHRP sexual and reproductive health and rights policies.

Giorgio et al., 2020; Gutiérrez Vázquez and Parrado, 2016; Samandari et al., 2012; Schiavon et al., 2012; Singh Thakuri et al., 2020) we account for individual-level determinants of reproductive behavior, including socio-demographic participant and household characteristics (e.g., women's education, urban/rural area of residence, region of residence), and other relevant characteristics (e.g., women's age, parity, and marital status at the time of each IPT, as well as reported exposure to domestic or intimate 
partner violence). Controlling for these characteristics, although they were unlikely to confound the effects of SRHRP, may increase the precision of our estimates.

Statistical analysis and model selection. We use multilevel logistic regression models with robust variance to consider the multistage probability sampling design with sampling within the neighborhood, to assess the magnitude of the direct associations between our dependent variables and SRHRPs. We also consider the survey weights to provide estimates that are generalizable to the entire 20-40 years female population. We report odds ratios (OR). We apply this analytical strategy to detect potential structural population changes.

To detect the best, if any, SRHRP operationalization, we compare Akaike information criterion (AIC) values and Bayesian information criterion (Values) (Raftery, 1995) from three model stages. The best models are the ones in which the difference between AIC or BIC values are the lowest and more than 10 among each other. In the first stage, we obtain values for baseline models, in which outcomes variables ('APC,' 'PWU,' and 'APC or PWU') are only adjusted by wave year. In the second stage, we obtain values for three different models adjusted by wave year and each SRHRP operationalization (partially adjusted). Lastly, we compare values for models in which all control variables are considered (fully adjusted).

To measure the proportion of the association mediated by modern contraceptive methods, access to contraceptive methods, and family conversations with health professionals, we divide their indirect association by the total effect. All statistical analyses are performed with Stata 16 and R.

\section{Results}

SHRP mapping. Our selection process (Fig. 1) determined a selection of twelve laws, eleven Supreme Court rulings, three national health plans, and eight executive actions (including decrees, resolutions, agreements, and circulars)-regarding abortion, contraceptive methods, family planning, sexual education, and sexual violence (see Fig. 2 and Table S2 in
Supplementary material for details). Our analysis shows that Colombia's policy approach to sexual and reproductive health and rights since 2000 involves simultaneous and contradictory forces depending on what dimensions of SRHRP are considered.

Family planning and contraception. Building on Colombia's PROFAMILIA family planning program implemented since the 1960s (Miller, 2010), executive actions put in place in the early 2000s emphasise public health and disease prevention through the provision of state-funded contraceptive methods (including emergency contraception) and family planning counseling, as well as childbirth and postpartum care (Resolution 412, 2000). Yet, from 2005 onwards, a slow shift towards the recognition of sexual, reproductive, and non-reproductive rights initiates through executive and legislative layering. Following a Supreme Court ruling condemning forced sterilizations committed on disabled women, the government's first National Sexual and Reproductive Health Plan (2002) begins shifting away from its previous public health and demographic approach. For this period, we observe the role of multiple state instruments in a transition towards a rights-based paradigm that emphasizes both individual autonomy and social responsibility. Sexual and reproductive rights are also, during the first decade of the century, incorporated as part of integral healthcare plans and other legal instruments (Women's integral health law or Law 823 (Law 823, 2003) and the National Public Health Plan (2007-2010) (Ministry of Social Protection, 2007)). In addition, the Colombian government adopts a set of policy instruments targeted at adolescent and children's sexual and reproductive health, including teenage pregnancy prevention and care (Law 1098, 2006; Law 1622, 2013). In 2008, state-based provision of contraceptive methods is seen as both a right and a means to reduce undesired pregnancy and maternal mortality by increasing knowledge and education on birth control of men, women, and heterosexual couples in the age of procreation (Resolution 769,2008 ). With the legalization of permanent, surgical contraceptive methods in 2010 (vasectomy and ligation of fallopian tubes) (Law 1412, 2010), Colombia's legislature deepens its reproductive rights approach and

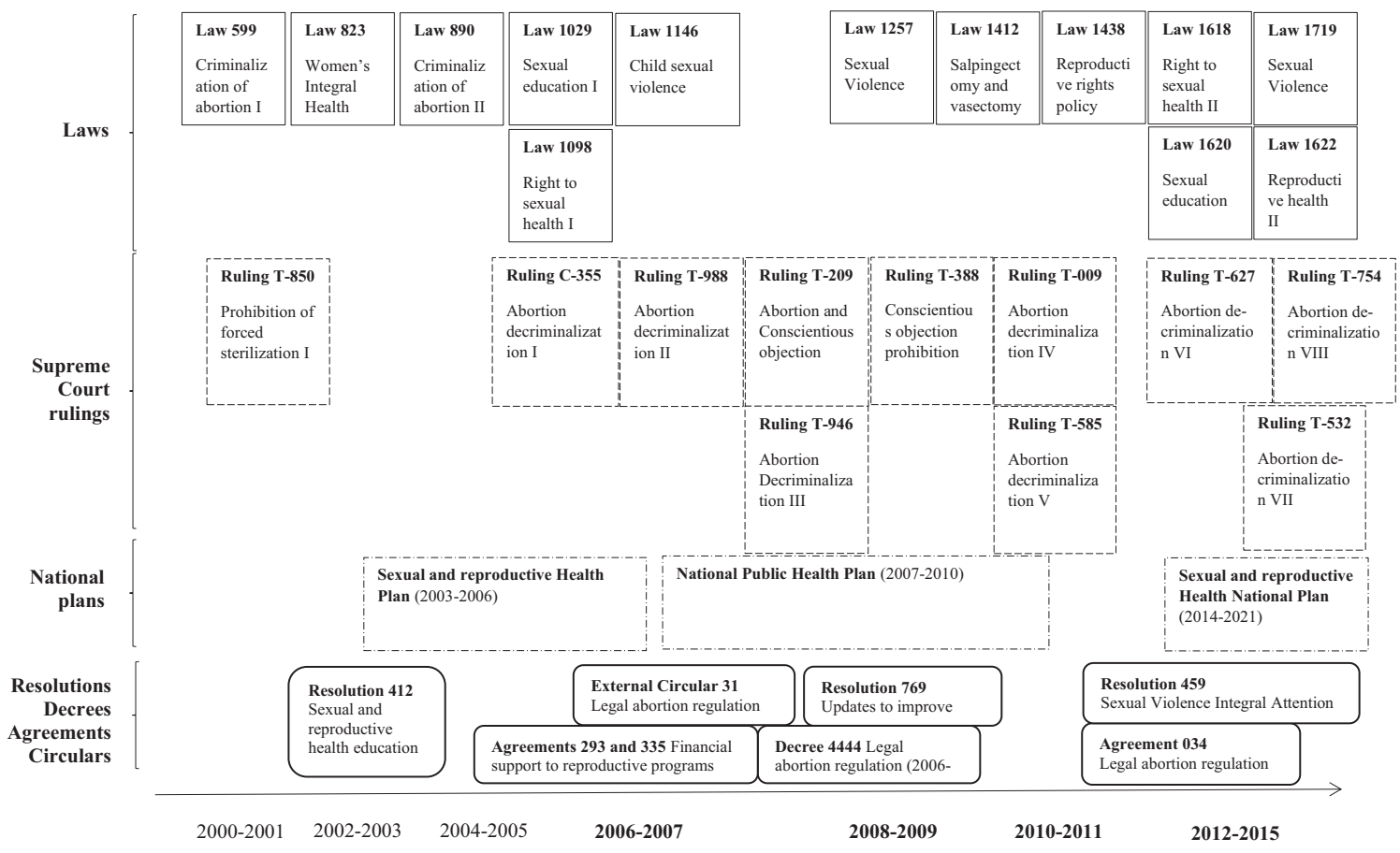

Fig. 2 Colombia's women's reproductive health policy changes over time (2000-2015). 
strengthens its legal framework (Law 1438, 2011; Statutory Law 1618, 2013). Finally, the second National Sexual and Reproductive Health Plan (2014-2021) (Política Nacional de Sexualidad, Derechos Sexuales y Derechos Reproductivos, 2014) marks a clear shift towards a social rights perspective, embracing sexuality as a key policy area and right.

Abortion rights. In May 2006, the Supreme Court ruling C-355 decriminalizes abortion for health or life-threatening circumstances, severe fetal malformation incompatible with life, sexual violence, or forced insemination-instituting a mixed legal regime in the country (Kulczycki, 2011). This decision retracts the penal code reforms of 2000 and 2004, which had increased prison sentences for women who terminated their pregnancies and the third parties assisting them. By declaring those restrictions unconstitutional, the ruling represents an important policy displacement, expanding sexual and reproductive rights in Colombia. Yet, in its aftermath, a set of executive and judicial decisions both moving forward and retracting from the court's decision unfold, reflecting interinstitutional conflicts and conservative backlashes. First, the technical norms regulating the provision of legal abortions in the public and private health care systems (Decree 4444, 2006), are transitorily suspended 3 years later by the country's highest administrative court, the Council of State, and declared null in 2013. In addition, challenges associated with the implementation of C-355 (2006) are widely reported and judicialized by women's organizations. Facing a lack of enforcement, the Supreme Court has since then ruled against discriminatory and unconstitutional practices, declaring them unnecessary barriers, burdens, and infringements on the right to intimacy and informed consent (C-754, 2015; T-209, 2008; T-532, 2014; T-627, 2012; T-946, 2008). In three other rulings (T-009, 2009; T-388, 2009; T-585, 2010), the court re-establishes the legal standards and obligations regarding access to voluntary abortions in the health care system. Yet, it is only in 2012 that misoprostol, a key drug for medical abortions, becomes covered by public health care (Agreement 034, 2012), in response to a Supreme Court ruling (T-627, 2012). In 2014, five years after the suspension of Decree 4444, the executive finally adopts a Technical Guide for Legal Abortion (Guía Técnica de Abortos No Punibles, 2010) and a Protocol for the Prevention of Unsafe Abortions (Prevención Del Aborto Inseguro En Colombia. Protocolo Para El Sector Salud., 2014), providing for the first-time health care professionals with guidelines regarding patients' attention, from the first medical counseling to post-abortion care. The pendulum movement resulting from interinstitutional conflicts on abortion regulation and implementation issues following the 2006 Supreme Court's C-355, illustrates a conflictive process of abortion liberalization in Colombia, which we theorize as a policy displacement with drifts.

Sexual education and sexual violence. Measures for sexual violence prevention and the integral attention of children, adolescents (Law 1146, 2007), and women who suffer sexual violence (Law 1257, 2008) are adopted in 2007 and 2008 in Colombia. Complemented with an executive protocol on sexual violence attention (Protocol and Model for the Integral Attention of Victims of Sexual Violence in the Healthcare System (Resolution $459,2012)$ ), Colombia also incorporates the right of sexual violence survivors to access emergency oral contraception, psychosocial assistance, and abortion freely and voluntarily. The protocol, along with the 2014 Law 1719, focuses on victims' access to justice, for example by removing the requirement for the formulation of criminal charges to request a legal abortion (Law 1719, 2014; Resolution 459, 2012). Yet, the Supreme Court ruling C-754 (2015), which reaffirms the mandatory implementation of the protocol, adds evidence to the lack of effective procedural guarantees and ongoing non-compliance by state institutions of existing legal instruments, representing serious obstacles for victims of sexual violence (Parra-Barrera et al., 2021). Moreover, despite the punitive evolution of sexual violence in the criminal code, Colombia does not count with a domestic instrument specifically dedicated to sexual violence. Then, even with the existence of provisions on sexual education since 1994, it is only five years later with the 2013 Ley de Convivencia Escolar, that sexual education is integrated into high school and university students' curricula in public and private schooling institutions (Law 1620, 2013a). Under the pressure of a network of academics and activists mobilized since the 1980s around sexual rights and sexology as a disciplinary field (Brigeiro and Facundo, 2013; Giami and Russo, 2013), this emerging framework indeed seeks the creation of human rights education training programs to promote adolescent physical, mental, and social wellbeing (Law $1620,2013 b)$. Through this legislation, Colombia acknowledges its role in both addressing sexual violence through education and protecting vulnerable populations that had long been ignored. Yet, insufficient legislative and executive efforts, as well as limited implementation, suggest a pattern of slow policy layering in the areas of sexual education and sexual violence prevention and sanction.

Assessments and effects of SRHRP as policy displacement; policy displacement with layering; and policy displacement with layering and drift. In this section, we assess different quantifications representing three operationalizations of SRHRP to further guide our interpretation of our policing mapping and the overall impact on our outcomes of interest.

Policy operationalizations of SRHRP and associations with pregnancy termination. Our three alternatives to model IPT outcomes (Supplementary Material Table S.3) suggest three main results: first, all "Partially adjusted models" significantly improve "Baseline models" when pregnancy termination is analyzed (differences are higher than 10 between models). Secondly, when "Partially adjusted models" are compared with "Fully adjusted ones", the latter significantly improves every IPT outcome. Lastly, when "Fully adjusted models" are compared across policies for the IPT outcomes, we observe that "Policy displacement with layering" and "Policy displacement with layering with drift" better capture PWU and ACF relative to "Policy displacement", and "Policy displacement with layering with drift" outperforms the other two policies when ACF is analyzed.

Two results for odds ratio (OR) between our three operationalizations of SRHRP and each outcome in partially adjusted models (Fig. 3) can be highlighted: first, each policy captures significant variation in IPT rates. Second, the highest reductions and smallest reductions are associated with "Policy displacement" and "Policy displacement with layering", respectively. A 45\% reduction in the OR of $\mathrm{ACF}(\mathrm{OR}=0.55$ Confidence Interval $(\mathrm{CI})$ 95\%: $0.36,0.74)$ corresponds to "Policy displacement". The lowest ORs are observed for "Policy displacement with layering" for PWU. A reduction of 19\% in reported IPTs (OR $=0.81$ (CI) 95\%: $0.76,0.87$ ) is observed. Fully adjusted models (Fig. 4) point to slightly more conservative results than partially adjusted ones, further confirming these associations (Tables S.4-S.6 are results of each fully adjusted model).

SRHRPs and associations with contraceptive method, family planning outreach activities, and provider of contraceptive methods. In terms of ORs (Fig. 5) we observe that policy displacement is consistently more associated with each of these outcomes, 


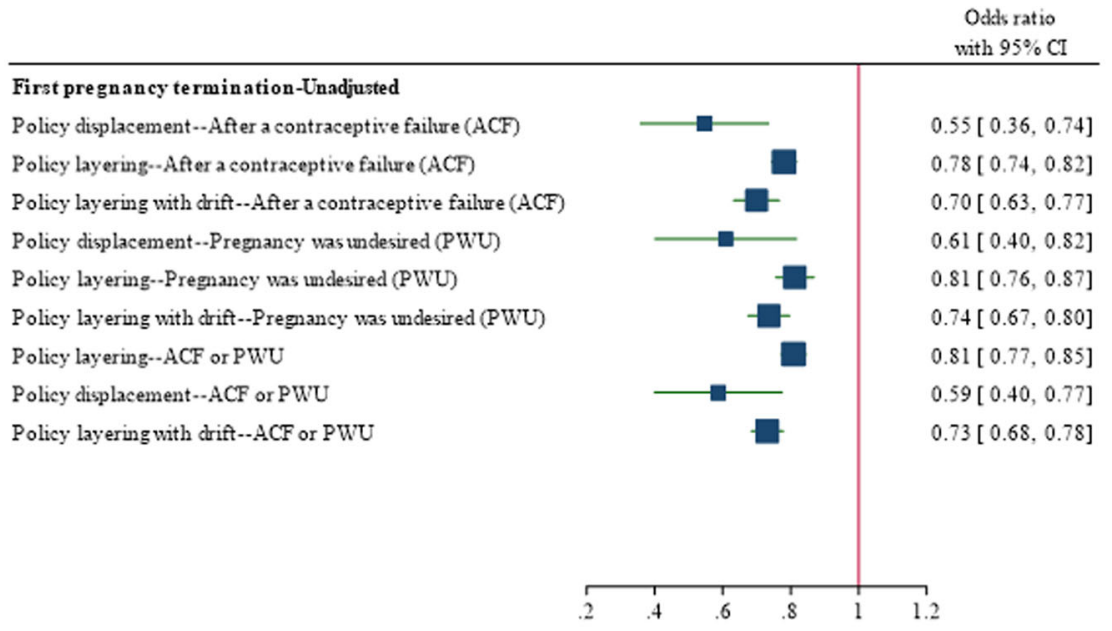

Unadjusted model considers year and policy.

Fig. 3 Odds ratio of induced pregnancy terminations (after a contraceptive failure (APC), pregnancy was undesired (PWU) and ACF or PWU) partially adjusted (Colombia 2000-2016; $N=81,760$ ).

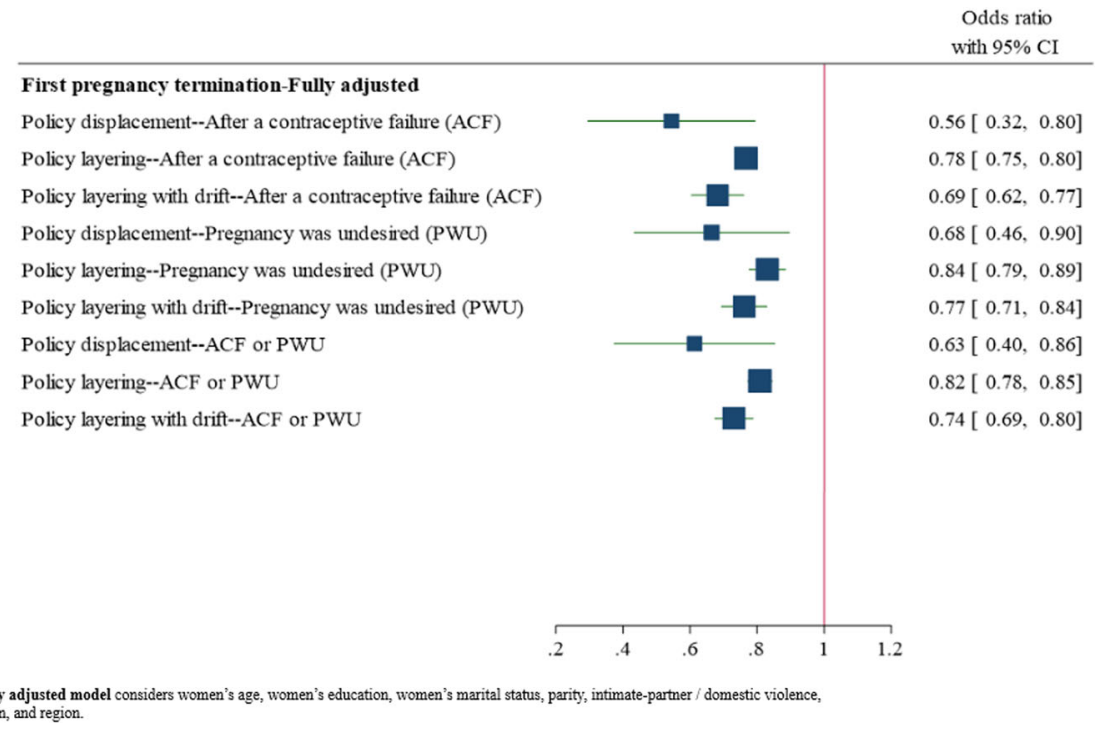

Fig. 4 Odds ratio of induced pregnancy terminations (after a contraceptive failure (APC), pregnancy was undesired (PWU) and ACF or PWU) fully adjusted (Colombia 2000-2016; $N=81,760$ ).

whereas "Policy displacement with layering" and "Policy displacement with layering and drift" are only associated with modern contraceptive methods. In "Fully adjusted models," "Policy displacement" increases the odds ratio of contraceptive methods-modern by $80 \%$ (OR:1.80 95\% CI: 1.60, 2.01), in "Family planning outreach activities" by $18 \%(\mathrm{OR}=1.1895 \mathrm{CI}$ : $1.04,1.31)$, and twice when the provider of contraceptive methods is the government (OR 2.14 95\% CI: 1.53, 2.75).

Mechanisms between SRHRP and pregnancy termination: contraceptive method, family planning outreach activities, and provider of contraceptive methods. The three mechanisms between SRHRP and pregnancy termination are presented in Fig. 6. When birth control, using modern methods as the reference group, is conceptualized as a mechanism between SRHRP and pregnancy termination, we observe that $13 \%$ (CI 95\%: 0.08, 0.18) of this association is explained by the "Policy displacement" option. This association is similar for the other two policy operationalisations with 7\% (CI 95\%: 0.02, 0.13) for "Policy displacement with layering" and 6\% (CI 95\%: 0.02, 0.13) for "Policy displacement with layering with drift". Regarding family planning outreach activities as a mechanism, we observe that only the association between "Policy displacement" and IPT is significantly explained by it. Lastly, when the mechanism is the government providing contraceptive methods, we detect significant and very similar relations for each policy operationalization. For "Policy displacement" 17\% (CI 95\%: 0.10, 0.24), for "Policy displacement with layering" 18\% (CI 95\%: 0.01, 0.35) and 13\% (CI 95\%: 0.01, 0.25) for "Policy displacement with drift."

\section{Discussion}

Mapping and simultaneously assessing SRHRP changes and impacts over time is a highly complex research endeavor. Our first set of results indicates that multiple policies are embedded in different state levels and propelled with different speeds and distinct degrees of implementation. These patterns of change result in a fuzzy institutional design which rightly prevents us, as initially suggested, from describing the evolution of SRHRP in monotonic terms. We observe rather that in Colombia, the simultaneous presence of layering with drifts, displacement with 


\begin{tabular}{|c|c|}
\hline & $\begin{array}{l}\text { Odds ratio } \\
\text { with } 95 \% \text { CI }\end{array}$ \\
\hline \multicolumn{2}{|l|}{ Contraceptive method-modern } \\
\hline Policy displacement-Partially adjusted & $1.74[1.58,1.91]$ \\
\hline Policy layering-Partially adjusted & $1.19[1.12,1.26]$ \\
\hline Policy layering with drift-Partially adjusted & $1.28[1.20,1.37]$ \\
\hline Policy displacement-Fully adjusted & $1.80[1.60,2.01]$ \\
\hline Policy layering-Fully adjusted & $1.23[1.18,1.28]$ \\
\hline Policy layering with drift-Fully adjusted & $1.21[1.12,1.30]$ \\
\hline \multicolumn{2}{|l|}{ Family planning outreach activities } \\
\hline Policy displacement-Partially adjusted & $1.22[1.07,1.36]$ \\
\hline Policy layering-Partially adjusted & $1.04[0.98,1.10]$ \\
\hline Policy layering with drift-Partially adjusted & $1.06[0.98,1.14]$ \\
\hline Policy displacement-Fully adjusted & $1.18[1.04,1.31]$ \\
\hline Policy layering-Fully adjusted & $1.04[0.98,1.09]$ \\
\hline Policy layering with drift-Fully adjusted & $1.05[0.97,1.13]$ \\
\hline \multicolumn{2}{|c|}{ Provider of contraceptive method-government } \\
\hline Policy displacement-Partially adjusted & $1.78[1.15,2.42]$ \\
\hline Policy layering-Partially adjusted & $1.04[0.79,1.29]$ \\
\hline Policy layering with drift-Partially adjusted & $1.04[0.68,1.39]$ \\
\hline Policy displacement-Fully adjusted & $2.14[1.53,2.75]$ \\
\hline Policy layering-Fully adjusted & $1.10[0.83,1.36]$ \\
\hline Policy layering with drift-Fully adjusted & $1.13[0.75,1.50]$ \\
\hline
\end{tabular}

Fig. 5 Odds ratio of contraceptive method-modern, family planning outreach activities, and provider of contraceptive methods-government partially and fully adjusted (Colombia 2000-2016; $N=81,760 ; N=49,493$ ).

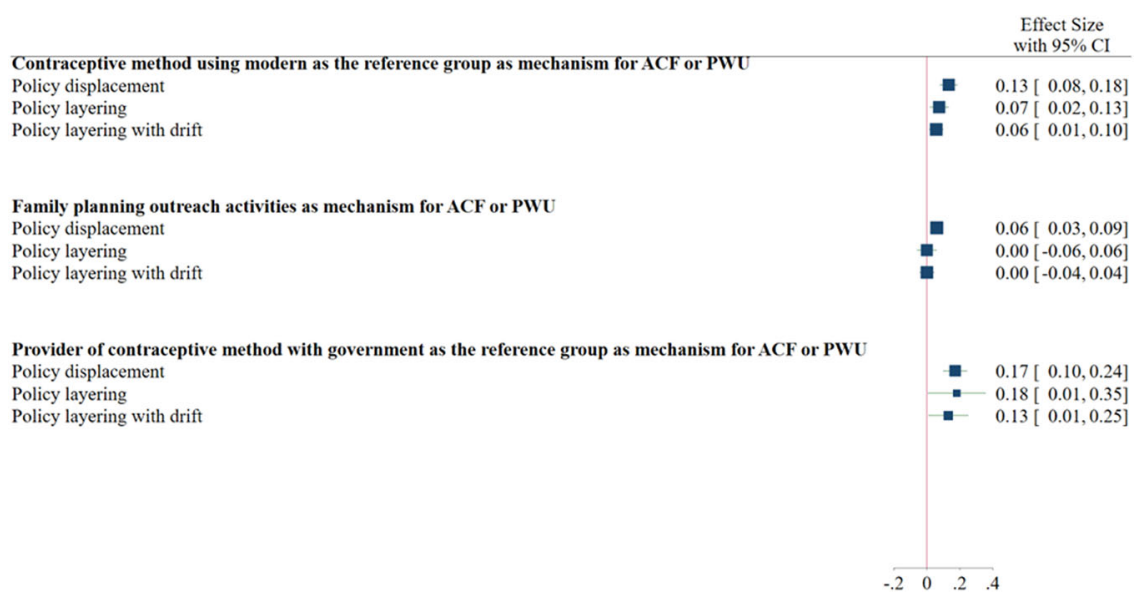

Fig. 6 Contraceptive method-modern, family planning outreach activities, and provider of contraceptive methods-government between policy displacement, policy layering, and policy displacement with layering and drift and induced pregnancy terminations (after a contraceptive failure (APC)), or pregnancy was undesired (PWU).

layering, and even late and weak attempts of SRHRP coexist for the period of 2000-2015. For instance, while family planning and contraception measures arrive at a degree of maturity at the beginning of 2010, norms to assist victims of sexual violence and prevent it, which have a direct incidence on access to IPTs under Colombia's current legal frame, only emerge in 2008 with the criminal code reform and operationalized in 2013 with the protocol of integral attention to victims. Yet, as evidenced by multiple Supreme Court rulings, non-compliance by state institutions is widespread. Similarly, as previous research has shown, abortion partial liberalization in Colombia suffers important implementation lacunes and heavily relies on civil society-based service 
provision (Amado et al., 2010; Moore et al., 2020, 2021; Stifani et al., 2018). While this dimension had a radical change in 2006 with the Supreme Court Ruling C-355, multiple attempts to challenge or bypass this ruling directly interfere with its implementations. State and social tensions emerged through the invocation by anti-abortion sectors of legal norms to protect health professionals' or judges' objection of conscience against practicing or ruling in favor of abortion cases (Ruibal, 2014).

The imbrication of Colombia's SRHRPs provokes immediate challenges on how these instruments should be operationalized when understanding both abortion changes over time and mechanisms associated with these variations. Our results confirm that nuances are necessary when constructing variables measuring SRHRP. Indeed 'policy displacement with layering' and 'policy displacement with layering with drift' are better operationalizations than 'policy displacement' when understanding abortion variation over time at the population level in Colombia -assuming these have direct effects on these outcomes. But only when resorting to our policy mapping results, we can confirm that the 'policy displacement with layering and drift' relative to 'policy displacement with layering' is qualitatively more adequate to capture the empirical variation observed in these outcomes. Granted, our quantitative operationalizations can be regarded, at best, as primitive rubrics to describe the drifts and layering associated with SRHRPs in Colombia. Indeed, our identification of both implementation and drift changes was based on very short scale time variation, even though we had access to 10 years of policy exposure.

In terms of outcomes, the $18 \%$ reduction in all reported IPT associated with 'policy displacement with layering' relative to the $26 \%$ reduction associated with 'policy displacement with layering with drift' suggests that a monotonic change as postulated by the former policy operationalization would be possible albeit that one acknowledges an extremely slow speed implementation process. On the other hand, the larger association with the former policy operationalization suggests that at different years within these 15 years of analysis, the proportion of abortions was very likely different from each other. For instance, when in 2013 the Law 1620 on sexual education is adopted, larger decreases in abortion could be expected after that period, relative to the 2006-2010 period. More specifically after 2013, individuals, particularly teenagers were more systematically exposed to sexual education policies that frame sexual rights as a means to enhancing their physical, mental, and social wellbeing, among other aspects, as well as a means to prevent unwanted adolescent pregnancy.

To better understand the relation between Colombia's SRHRP and IPTs, we explored three potential mechanisms. Our first mechanism was identifying the extent to which changes in contraceptive practices mediated SHRP and abortion. Our results suggest that SHRP changes are associated with greater use of modern contraceptive methods such as emergency contraception, pill, IUD, injection, permanent surgical methods, condoms, and implants. More specifically, this shift is associated with a $6 \%$ association between SRHRPs' 'policy displacement with layering' and abortion. Our results, therefore, suggest that increases in effective contraceptive methods, such as those regarded as modern, could lead to fewer unwanted pregnancies, and therefore proportionally fewer women facing decisions to abort in potentially unsafe conditions.

A second mechanism was whether access to family planning services was correlated with this outcome after SRHRPs moved forward. As it has been argued, structural shifts can be observed in the number of abortions when family planning conversations take place between women and health professionals (Roberts et al., 2017). While an increment of this type of encounters over time was observed, these encounters did not mediate the association between pregnancy termination and SRHRP's 'displacement with layering.' However, family planning services mediated by $6 \%$ the association between abortion and SRHRP's 'displacement' operationalization. This result is extremely interesting because our policy mapping does not correspond to a case of SRHRP displacement, suggesting that these results need to be taken with extreme caution. Nevertheless, this opens two avenues of research. First, while conversations between women and health professionals increased in terms of family planning, it is important to better determine the type, quality, and timing of these conversations-as well as establishing the role played by male partners in the discussion and heterosexual couples' birth control practices. Second, regional analyses of this country should be advanced to assess whether differences across subnational regions exist. It is possible that our conceptualization of SRHRP at the national level masked regional variation. In short, it is possible that only in certain regions an increase of family planning services was mediating the association between SRHRP and abortion rates.

Our third mechanism, whereby the government facilitates the provision of contraceptive methods, significantly mediates abortion rates in Colombia in each policy operationalization we used. For instance, $13 \%$ of the decrease association between 'policy displacement with layering and drift' and pregnancy terminations is explained by this mechanism. This illustrates that an effective avenue of policy implementation in this realm is when governments increase access to affordable modern contraceptive methods. In Colombia, this significantly augments particularly since the 2005 National Public Health Plan or the Resolution 769-2008, which included the state-based provision of contraceptive methods.

A note of caution is due. Part of the existing research on the effects on SRHRP and pregnancy termination focuses on macrolevel changes in official statistics of abortion-related complications. These data, however, only capture abortions that occur within health care systems, leaving unaccounted informal sector abortions (Chemlal and Russo, 2019) - a problem our study intends to address indirectly, not without flaws. While surveys such as the DHS are well designed to deal with privacy and intimacy challenges, cultural stigma and taboo related to IPT may still generate significant underreporting, as well as within and between-case inconsistencies (DHS Program, 2018). Another element not discussed in this study was group heterogeneity. Indeed, while we offer a general account of how SRHRPs may have operated at the female population level, it is possible that specific subgroups such as women exposed to forced migration and/or conflict-related violence were driving results to other directions (Peralta Jimenez and Urrego Mendoza, 2020). As such, more research is needed to unpack the impacts of SRHRPs on different socioeconomic and racial groups of women in multiple regional settings in Colombia, and thus fleshing out our understanding of the effects of Colombia's SRHP for the analyzed period. Furthermore, the remarkably high prevalence of female sterilization $(44.1 \%$ in 2010 among women of reproductive age using a contraceptive method) in Colombia (Folch et al., 2017, p. 1773), demands a careful assessment. While suspicions over targeted sterilizations amongst vulnerable groups in Colombia have been partly dissipated (Leite et al., 2004), forced sterilizations, unconsented contraceptive intake, and abortion amongst poor, racialized, and disabled women in the context of the armed conflict in Colombia have been reported by civil society organizations (Centro de Derechos Reproductivos, 2020). These studies signal that our study's results cannot be taken as the face value of improvements in women's reproductive empowerment. Lastly, the description of our policy mapping process does not fully integrate how collective behaviors, from groups supporting 
women's rights, or conservative ones, had an impact on Colombia's SRHRP evolution. Incorporating these actions, particularly those carried out by civil society ones that support women's right, are essential to understand the aforementioned quantitative associations. More specifically, while these organizations address purposely the state to influence policy outcomes, they simultaneously have the capacity to influence women's behavior and therefore some of the variation of IPT here described is likely explained by dialogs between women and civil society organizations. Ultimately, these limitations should temper our results and interpretations.

To conclude, by empirically testing the pertinency of three operationalizations of SRHRP, our paper signals at least three avenues of research and an overall reflection associated with this debate. First, more efforts to theorize policy changes and continuities should be advanced. While our study suggested three categories, others should for instance incorporate the notion of pace, by considering exponential or very slow changes rather than gradual ones. For this, it is essential that a combination of methods is carried out. Considering the mapping of policies in a systematic manner can better inform quantitative operationalizations to avoid statistical artifacts. Second, using different outcomes, such as changes in both men and women's knowledge over sexual and reproductive rights including abortion and birth control options, but more broadly, the gender gap in such knowledge, could provide better insights regarding the limits and overlaps of SRHRP operationalizations, and even further understand the extent under which gender inequality has been reduced. While our study pointed out that significant changes in reported IPT rates and SRHRP were mediated by two mechanisms, more attention is needed to study other mechanisms which could complement our understanding of this association. For instance, qualitative research would indeed be particularly well-suited to evaluate women's degree of agency in their sexual and reproductive health decision-making, particularly in a context where both conflict-related and gender-based violence are pervasive (Gomez, 2011; Pallitto and O'Campo, 2004; Peralta Jimenez and Urrego Mendoza, 2020). Third, women's access to other sexual and reproductive health services and information through civil society networks and organizations, currently considered as the largest abortion providers in the country (DePiñeres et al., 2017; Stifani et al., 2018) are some of the areas that could better explain how civil society forces may have anticipated or reinforced SRHRP efforts in Colombia. Last, in concordance with the conclusions of the last report of the Guttmacher-Lancet Commission (Starrs et al., 2018), our results call for more concretizing rightsbased approaches to sexual and reproductive health in which efforts to reduce multiple barriers to policy implementation are required. Indeed, the existence of underlying conditions affecting both the state's capacity to enact policies and the ability of women and girls-as a function of various conditions which make them vulnerable to societal forces such as structural racism or structural violence-to exercise their sexual and reproductive rights, including accessing safe abortion services, are elements that need to be fully accounted to both understand and obtain all the targets related to the SDG 5: Achieve gender equality and empower all women and girls.

\section{Data availability}

All data and codes are available in the following depository: Nazif-Munoz, Jose Ignacio; Chabot, Rose, 2021, "Mapping and assessing sexual and reproductive health policy changes over time in Colombia: measuring their impact on pregnancy terminations.", https://doi.org/10.7910/DVN/8OK44T, Harvard Dataverse, V1, UNF:6:vYCkePWYLBBof2RavBFGNQ==[fileUNF].
Received: 30 July 2021; Accepted: 13 December 2021; Published online: 06 January 2022

\section{References}

Agreement 034 (2012) Comisión de Regulación en Salud de la República de Colombia. https://www.minsalud.gov.co/Normatividad_Nuevo/Acuerdo\% 20034\%20de\%202012.pdf

Amado ED, Calderón García MC, Cristancho KR, Salas EP, Hauzeur EB (2010) Obstacles and challenges following the partial decriminalisation of abortion in Colombia. Reprod Health Matters 18(36):118-126. https://doi.org/ 10.1016/S0968-8080(10)36531-1

Bélanger D, Flynn A (2009) The persistence of induced abortion in Cuba: exploring the notion of an "abortion culture". Stud Fam Plan 40(1):13-26. https:// doi.org/10.1111/j.1728-4465.2009.00183.x

Benson J (2005) Evaluating abortion-care programs: old challenges, new directions. Stud Fam Plan36(3):189-202. https://doi.org/10.1111/j.1728 4465.2005.00061.x

Blank RM, George CC, London RA (1994) State Abortion Rates: the impact of policies, providers, politics, demographics, and economic environment. NBER Working Paper Series, No. 4853, 70

Brenes-Monge A, Yáñez-Álvarez I, Menese-León J, Poblano Verástegui O, VertizRamírez J, de J, Saturno-Hernández PJ (2020) Aproximación a la calidad de la atención durante el embarazo, parto y posparto en mujeres con factores de riesgo obstétrico en México. Salud Pública Méx 62(6, Nov-Dic):798-809. https://doi.org/10.21149/11974

Brigeiro M, Facundo A (2013) Between avant-garde ideals and conservative moralities: the emergence of sexology in Colombia. Int J Sexual Health 25(1):75-91. https://doi.org/10.1080/19317611.2012.759635

Budde E, Heichel S (2017) Women Matter: the impact of gender empowerment on abortion regulation in 16 European Countries between 1960 and 2010. Politics Gender 13(2017):432-457

C-754 (2015) Corte Constitucional de Colombia. https://www.corteconstitucional. gov.co/RELATORIA/2015/C-754-15.htm

Casterline J, Mendoza J (2009) Unwanted fertility in Latin America: Historical trends, recent patterns

Centro de Derechos Reproductivos (2020) Reporte Violencia Reproductiva en el conflicto armado colombiano. Una mirada con lentes de género y derechos reproductivos. https://reproductiverights.org/our-regions/latin-america-caribbean/

Chemlal S, Russo G (2019) Why do they take the risk? A systematic review of the qualitative literature on informal sector abortions in settings where abortion is legal. BMC Women's Health 19(1):55. https://doi.org/10.1186/s12905-0190751-0

Clarke D, Mühlrad H (2018) Abortion laws and womens health. IZA-Institute of Labor Economics, No. 11890. https://doi.org/10.1016/j.jhealeco.2020.102413

Corte Constitucional de Colombia (2006) C-355/06. Corte Constitucional de Colombia

Decree 4444 (2006) Ministerio de la Protección Social. http://www.suin juriscol.gov.co/viewDocument.asp?ruta $=$ Decretos $/ 1546197$

Darney BG, Fuentes-Rivera E, Saavedra-Avendaño B, Sanhueza-Smith P, Schiavon R (2020) Contraceptive receipt among first-trimester abortion clients and postpartum women in urban Mexico. Int Perspect Sexual Reprod Health 46(1):35-43

Denisov BP, Sakevich VI, Jasilioniene A (2012) Divergent trends in abortion and birth control practices in Belarus, Russia and Ukraine. PLOS ONE 7(11):e49986. https://doi.org/10.1371/journal.pone.0049986

DePiñeres T, Raifman S, Mora M, Villarreal C, Foster DG, Gerdts C (2017) 'I felt the world crash down on me': women's experiences being denied legal abortion in Colombia. Reprod Health 14(1):133. https://doi.org/10.1186/ s12978-017-0391-5

DHS Program (2018) The DHS Program-consistency of reporting of terminated pregnancies in DHS calendars (English). https://dhsprogram.com/ publications/publication-mr25-methodological-reports.cfm

Fetters MD, Curry LA, Creswell JW (2013) Achieving integration in mixed methods designs-principles and practices. Health Serv Res 48(6 part 2):2134-2156. https://doi.org/10.1111/1475-6773.12117

Fischer S, Royer H, White C (2018) The impacts of reduced access to abortion and family planning services on abortions, births, and contraceptive purchases. J Public Econ 167:43-68. https://doi.org/10.1016/j.jpubeco.2018.08.009

Flórez CE, Soto VE (2007) Fecundidad Adolescente y Desigualdad en Colombia y la Región de América Latina y el Caribe. Comisión Económica para América Latina y el Caribe

Folch BM, Betstadt S, Li D, Whaley N (2017) The rise of female sterilization: a closer look at Colombia. Matern Child Health J 21(9):1772-1777. https:// doi.org/10.1007/s10995-017-2296-x

Forman-Rabinovici A, Sommer U (2018) Reproductive health policy-makers: comparing the influences of international and domestic institutions on abortion policy. Public Adm 96(1):185-199. https://doi.org/10.1111/ padm. 12383 
Gambetta D (1998) Concatenations of mechanisms. In: Hedström P, Swedberg R (Eds) Social mechanisms: an analytical approach to social theory. Cambridge University Press.

Ganatra B, Faundes A (2016) Role of birth spacing, family planning services, safe abortion services and post-abortion care in reducing maternal mortality. Best Pract Res Clin Obstet Gynaecol 36:145-155. https://doi.org/10.1016/ j.bpobgyn.2016.07.008

Ganatra B, Gerdts C, Rossier C, Johnson BR, Tunçalp Ö, Assifi A, Sedgh G, Singh S, Bankole A, Popinchalk A, Bearak J, Kang Z, Alkema L (2017) Global, regional, and subregional classification of abortions by safety, 2010-14: estimates from a Bayesian hierarchical model. The Lancet 390(10110):2372-2381. https://doi.org/10.1016/S0140-6736(17)31794-4

Giami A, Russo J (2013) The diversity of sexologies in Latin America: emergence, development, and diversification. Int J Sexual Health 25(1):1-12. https:// doi.org/10.1080/19317611.2012.760507

Giorgio U, Soeharno A, Besral S, Philbin S, Sedgh (2020) Estimating the Incidence of Induced Abortion in Java, Indonesia, 2018. Int Perspect Sexual Reprod Health 46:211. https://doi.org/10.1363/46e0220

Gomez AM (2011) Sexual violence as a predictor of unintended pregnancy, contraceptive use, and unmet need among female youth in Colombia. J Women's Health 20(9):1349-1356. https://doi.org/10.1089/jwh.2010.2518

Guía Técnica de Abortos No Punibles, Salud, Ministerio de la __ (Presidencia de la Nación 2010).

Gutiérrez Vázquez EY, Parrado EA (2016) Abortion legalization and childbearing in Mexico: abortion legalization and childbearing in Mexico. Stud Fam Plan 47(2):113-128. https://doi.org/10.1111/j.1728-4465.2016.00060.x

van der Heijden J, Kuhlmann J (2017) Studying incremental institutional change: a systematic and critical meta-review of the literature from 2005 to 2015. Policy Stud J 45(3):535-554. https://doi.org/10.1111/psj.12191

Jaffré Y, Suh S (2016) Where the lay and the technical meet: using an anthropology of interfaces to explain persistent reproductive health disparities in West Africa. Soc Sci Med 156:175-183. https://doi.org/10.1016/j.socscimed.2016.03.036

Karp C, Wood SN, Galadanci H, Sebina Kibira SP, Makumbi F, Omoluabi E, Shiferaw S, Seme A, Tsui A, Moreau C (2020) 'I am the master key that opens and locks': presentation and application of a conceptual framework for women's and girls' empowerment in reproductive health. Soc Sci Med 258:113086. https://doi.org/10.1016/j.socscimed.2020.113086

Khan S, Hancioglu A (2019) Multiple indicator cluster surveys: delivering robust data on children and women across the globe. Stud Fam Plan 50(3):279-286. https://doi.org/10.1111/sifp.12103

Kulczycki A (2011) Abortion in Latin America: changes in practice, growing conflict, and recent policy developments. Stud Fam Plan 42(3):199-220. https://doi.org/10.1111/j.1728-4465.2011.00282.x

Lane SD (1994) From population control to reproductive health: an emerging policy agenda. Soc Sci Med 39(9):1303-1314. https://doi.org/10.1016/02779536(94)90362-X

Law 1098 (2006) Congreso de Colombia. http://www.suin-juriscol.gov.co/ viewDocument.asp?ruta $=$ Leyes $/ 1673639$

Law 1146 (2007) Congreso de Colombia. http://www.suin-juriscol.gov.co/ viewDocument.asp?ruta $=$ Leyes $/ 1674826 \#: \sim$ :text $=$ LEY\% $201146 \% 20 \mathrm{DE} \%$ 202007\&text=(julio\%2010)-,por\%20medio\%20de\%20la\%20cual\%20se\% 20expiden\%20normas\%20para\%20la,ni\%C3\%Blas\%20y\%20adolescentes\% 20abusados\%20sexualmente.

Law 1412 (2010) Congreso de Colombia. http://www.secretariasenado.gov.co/ senado/basedoc/ley_1412_2010.html

Law 1438 (2011) Congreso de Colombia. http://www.suin-juriscol.gov.co/ viewDocument.asp?ruta $=$ Leyes $/ 1680431$

Law 1620 (2013a) Congreso de Colombia (testimony of Congreso de Colombia). http://www.suin-juriscol.gov.co/viewDocument.asp?id=1672916

Law 1620 (2013b) Congreso de Colombia. https://www.funcionpublica.gov.co/eva/ gestornormativo/norma.php?i $=52287$

Law 1622 (2013) Congreso de Colombia. http://www.suin-juriscol.gov.co/ viewDocument.asp?ruta $=$ Leyes $/ 1685451$

Law 1719 (2014) Congreso de Colombia (2014) https://secretariageneral.gov.co/ transparencia/control/informaci\%C3\%B3n-poblaci\%C3\%B3n-vulnerable/ley1719-2014

Law 823 (2003) Congreso de Colombia (testimony of Congreso de Colombia). http://www.suin-juriscol.gov.co/viewDocument.asp?ruta=Leyes/ 1669075\#: :text=La\%20presente\%20ley\%20tiene\%20por,los\%20\%C3\% Almbitos\%20p\%C3\%BAblico\%20y\%20privado

Leite IDC, Gupta N, Rodrigues RDN (2004) Female sterilization In Latin America: cross-national perspectives. J Biosoc Sci 36(6):683-698. https://doi.org/ $10.1017 /$ S0021932003006369

Levine PB, Staiger D (2004) Abortion policy and fertility outcomes: the Eastern European experience. J Law Econ 47(1):223-243. https://doi.org/10.1086/380475

Magnani RJ, Rutenberg N, McCann HG (1996) Detecting induced abortions from reports of pregnancy terminations in DHS Calendar Data. Stud Fam Plan 27(1):36. https://doi.org/10.2307/2138076
Maldonado OJ (2019) The decriminalisation of abortion in Colombia as cautionary tale. Social movements, numbers and socio-technical struggles in the promotion of health as a right. Global Public Health 14(6-7):1031-1043. https:// doi.org/10.1080/17441692.2018.1504101

Miller G (2010) Contraception as development? New evidence from family planning in Colombia. Econ J 120(545):709-736. https://doi.org/10.1111/j.14680297.2009.02306.x

Ministry of Justice of Colombia (2021) SUIN-Juriscol. http://www.suinjuriscol.gov.co/

Ministry of Social Protection (2007) Plan Nacional de Salud Pública 2007-2010. Government of Colombia.

Moore AM, Blades N, Ortiz J, Whitehead H, Villarreal C (2020) What does informal access to misoprostol in Colombia look like? A mystery client methodology in Bogotá and the Coffee Axis. BMJ Sexual Reprod Health 46(4):294-300. https://doi.org/10.1136/bmjsrh-2019-200572

Moore AM, Ortiz J, Blades N, Whitehead H, Villarreal C (2021) Women's experiences using drugs to induce abortion acquired in the informal sector in Colombia: Qualitative interviews with users in Bogotá and the Coffee Axis. Sexual Reprod Health Matters 29(1):1890868. https://doi.org/10.1080/ 26410397.2021.1890868

OECD (2020) Gender Equality in Colombia: access to justice and politics at the local level | en | OECD. https://www.oecd.org/social/gender-equality-incolombia-b956ef57-en.htm

Onwuegbuzie AJ, Bustamante RM, Nelson JA (2010) Mixed research as a tool for developing quantitative instruments. J Mixed Methods Res 4(1):56-78 https://doi.org/10.1177/1558689809355805

Pallitto CC, O'Campo P (2004) The relationship between intimate partner violence and unintended pregnancy: analysis of a national sample from Colombia. Int Fam Plan Perspect 30(4):165-173. https://doi.org/10.1363/3016504

Parra-Barrera S, Moyano N, Boldova M, Sánchez-Fuentes M (2021) Protection against sexual violence in the Colombian Legal Framework: obstacles and consequences for women victims. Int J Environ Res Public Health 18(8):4171. https://doi.org/10.3390/ijerph18084171

Peirö R, Colomer C, Alvarez-Dardet C, Ashton JR (2001) Does the liberalisation of abortion laws increase the number of abortions?: the case study of Spain. Eur J Public Health 11(2):190-194. https://doi.org/10.1093/eurpub/11.2.190

Peralta Jimenez JA, Urrego Mendoza ZC (2020) Salud sexual y reproductiva en mujeres víctimas del conflicto armado. Rev Salud Pública 22(4). https:// doi.org/10.15446/rsap.v22n4.88576

Política Nacional de Salud Sexual y Reproductiva (2002-2006) (2002) Testimony of República de Colombia \& Ministerio de la Protección Social Dirección General de Salud Pública

Política Nacional de Sexualidad, Derechos Sexuales y Derechos Reproductivos (2014) Testimony of Profamilia, Ministerio de Salud y Protección Social, \& Fondo de Población de las Naciones Unidas (UNFPA). http://www.suinjuriscol.gov.co/viewDocument.asp? ruta $=$ Decretos $/ 1509366$

Prada E, Biddlecom A, Singh S (2011) Induced abortion in Colombia: new estimates and change between 1989 and 2008. Int Perspect Sexual Reprodu Health 37(03):114-124. https://doi.org/10.1363/3711411

Prada E, Singh S, Villarreal C (2012) Health consequences of unsafe abortion in Colombia, 1989-2008. Int J Gynecol Obstet 118:S92-S98. https://doi.org/ $10.1016 /$ S0020-7292(12)60006-X

Prevención del Aborto Inseguro en Colombia. Protocolo para el Sector Salud (2014) Ministerio de Salud y Protección Social, Fondo de Población de las Naciones Unidas (UNFPA). https://www.minsalud.gov.co/sites/rid/Lists/ BibliotecaDigital/RIDE/VS/PP/SM-Protocolo-IVE-ajustado-.pdf

Raftery AE (1995) Bayesian model selection in social research. Sociol Methodol 25:111-163. https://doi.org/10.2307/271063

Reingold B, Kreitzer RJ, Osborn T, Swers ML (2021) Anti-abortion policymaking and women's representation. Political Res Q 74(2):403-420. https://doi.org/ $10.1177 / 1065912920903381$

Resolution 412 (2000) Ministerio de Salud y Protección Social. https:// www.minsalud.gov.co/Normatividad_Nuevo/Resoluci\%C3\%B3n\%204905\% 20de\%202006.PDF

Resolution 459 (2012) Ministerio de Salud y Protección Social. https:// www.minsalud.gov.co/sites/rid/Lists/BibliotecaDigital/RIDE/DE/DIJ/ Resolucion-0459-de-2012.PDF

Resolution 769 (2008) Ministerio de la Protección Social. https:// www.defensoria.gov.co/public/pdf/11/salud/r769_08.pdf

Roberts SCM, Fuentes L, Berglas NF, Dennis AJ (2017) A 21st-century public health approach to abortion. Am J Public Health 107(12). https:// ajph.aphapublications.org/doi/full/10.2105/AJPH.2017.304068

Ruibal A(2014) Movement and counter-movement: a history of abortion law reform and the backlash in Colombia 2006-2014. Reprod Health Matters 22(44):42-51. https://doi.org/10.1016/S0968-8080(14)44803-1

Samandari G, Wolf M, Basnett I, Hyman A, Andersen K (2012) Implementation of legal abortion in Nepal: a model for rapid scale-up of high-quality care. Reprod Health 9(1):7. https://doi.org/10.1186/1742-4755-9-7 
Schiavon R, Troncoso E, Polo G (2012) Analysis of maternal and abortion-related mortality in Mexico over the last two decades, 1990-2008. Int J Gynecol Obstetrics 118(S2):S78-S86. https://doi.org/10.1016/S0020-7292(12)60004-6

Sedgh G, Singh S, Shah IH, Åhman E, Henshaw SK, Bankole A (2012) Induced abortion: Incidence and trends worldwide from 1995 to 2008. The Lancet 379(9816):625-632. https://doi.org/10.1016/S0140-6736(11)61786-8

Singh S, Wulf D (1994) Estimated levels of induced abortion in six Latin American countries. Int Fam Plan Perspect 20(1):4. https://doi.org/10.2307/2133331

Singh Thakuri D, Raj Ghimire P, Poudel S, Bahadur Khatri R (2020) Association between intimate partner violence and abortion in Nepal: a pooled analysis of Nepal demographic and health surveys (2011 and 2016). BioMed Res Int 2020. https://www.hindawi.com/journals/bmri/2020/5487164/

Staggenborg S, Skoczylas MB (2017) Battles over Abortion and Reproductive Rights. In: McCammon HJ, Taylor V, Reger J, Einwohner RL (Eds), The Oxford Handbook of US Women's Social Movement Activism (pp. 214-231). Oxford University Press

Starbird E, Norton M, Marcus R (2016) Investing in family planning: key to achieving the sustainable development goals. Global Health: Sci Pract 4(2):191-210

Starrs AM, Ezeh AC, Barker G, Basu A, Bertrand JT, Blum R, Coll-Seck AM, Grover A, Laski L, Roa M, Sathar ZA, Say L, Serour GI, Singh S, Stenberg K, Temmerman M, Biddlecom A, Popinchalk A, Summers C, Ashford LS (2018) Accelerate progress-sexual and reproductive health and rights for all: report of the Guttmacher-Lancet Commission. The Lancet 391(10140):2642-2692. https://doi.org/10.1016/S0140-6736(18)30293-9

Statutory Law 1618 (2013) Congreso de Colombia, 41. https:// www.minsalud.gov.co/sites/rid/Lists/BibliotecaDigital/RIDE/DE/PS/ documento-balance-1618-2013-240517.pdf

Stephenson R, Gonsalves L, Askew I, Say L, WHO Working Group for Operationalizing Sexual Health (2017) Detangling and detailing sexual health in the SDG era. Lancet 390(10099):1014-1015. https://doi.org/10.1016/S01406736(17)32294-8

Stifani BM, Urbano LG, Velez ACG, Velásquez CV (2018) Abortion as a human right: The struggle to implement the abortion law in Colombia. Int J Gynecol Obstet 143(S4):12-18. https://doi.org/10.1002/ijgo.12672

Supreme Court of Colombia (2021) Consulta de Jurisprudencia. http:// consultajurisprudencial.ramajudicial.gov.co:8080/WebRelatoria/csj/index.xhtml

T-009 (2009) Corte Constitucional de Colombia. https://www.corteconstitucional. gov.co/relatoria/2009/T-009-09.html

T-209 (2008) Corte Constitucional de Colombia. https://www.corteconstitucional. gov.co/relatoria/2008/t-209-08.html

T-388 (2009) Corte Constitucional de Colombia. https://www.corteconstitucional. gov.co/relatoria/2009/t-388-09.html

T-532 (2014) Corte Constitucional de Colombia. https://www.corteconstitucional. gov.co/relatoria/2014/t-532-14.html

T-585 (2010) Corte Constitucional de Colombia. https://www.corteconstitucional. gov.co/relatoria/2010/t-585-10.html
T-627 (2012) Corte Constitucional de Colombia. https://www.corteconstitucional. gov.co/relatoria/2012/t-627-12.html

T-946 (2008) Corte Constitucional de Colombia. https://www.corteconstitucional. gov.co/relatoria/2008/T-946-08.html

UNFPA (2021) United Nations Populations Fund. Decade of action: sustainable development goals (2015). https://www.unfpa.org/sdg

\section{Acknowledgements}

We would like to acknowledge the feedback provided by participants from the annual meeting of the Canadian Population Society 2021 and the 5th International Conference on Public Policy (ICPP5) Barcelona. We would like to acknowledge the funding contribution made by the Fonds de recherche Santé, grant \# 269540, and Fonds démarrage provided by the Université de Sherbrooke.

\section{Competing interests}

The authors declare no competing interests.

\section{Additional information}

Supplementary information The online version contains supplementary material available at https://doi.org/10.1057/s41599-021-01016-0.

Correspondence and requests for materials should be addressed to José Ignacio NazifMunoz.

Reprints and permission information is available at http://www.nature.com/reprints

Publisher's note Springer Nature remains neutral with regard to jurisdictional claims in published maps and institutional affiliations.

\begin{abstract}
cc) (i) Open Access This article is licensed under a Creative Commons c. Attribution 4.0 International License, which permits use, sharing, adaptation, distribution and reproduction in any medium or format, as long as you give appropriate credit to the original author(s) and the source, provide a link to the Creative Commons license, and indicate if changes were made. The images or other third party material in this article are included in the article's Creative Commons license, unless indicated otherwise in a credit line to the material. If material is not included in the article's Creative Commons license and your intended use is not permitted by statutory regulation or exceeds the permitted use, you will need to obtain permission directly from the copyright holder. To view a copy of this license, visit http://creativecommons.org/ licenses/by/4.0/.
\end{abstract}

(C) The Author(s) 2022 